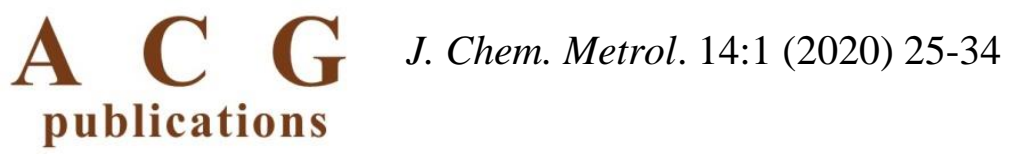

\title{
Determination of secondary metabolites of Origanum vulgare subsp. hirtum and $O$. vulgare subsp. vulgare by LC-MS/MS
}

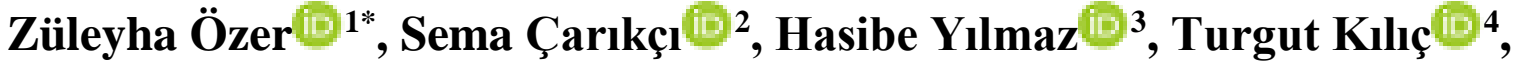 Tuncay Dirmenci ${ }^{5}$ and Ahmet C. Gören $\odot{ }^{6,7 *}$}

\footnotetext{
${ }^{1}$ Medicinal and Aromatic Plants Programme, Altinoluk Vocational School, Balikesir University, Edremit-Balikesir, Türkiye

${ }^{2}$ Vocational School, Izmir Democracy University, Izmir, Türkiye

${ }^{3}$ TUBITAK UME, Chemistry Group, Organic Chemistry Laboratory, Gebze, Kocaeli, Türkiye

${ }^{4}$ Department of Science Education, Necatibey Faculty of Education, Balikesir University, Balikesir, Türkiye

${ }^{5}$ Department of Biology Education, Necatibey Faculty of Education, Balikesir University, Balikesir, Türkiye

${ }^{6}$ Drug Application and Research Center (ILMER), Bezmialem Vakif University, Istanbul, Türkiye

${ }^{7}$ Faculty of Pharmacy, Department of Analytical Chemistry, Bezmialem Vakif University, Istanbul, Türkiye
}

(Received April 08, 2020; Revised May 07, 2020; Accepted May 09, 2020)

\begin{abstract}
Secondary metabolites of solvent extracts of Origanum vulgare subsp. hirtum and $O$. vulgare subsp. vulgare were determined using liquid chromatography-mass spectrometry (LC-MS/MS). Curcumin was used as an internal standard. Rosmarinic acid was determined as the main compound of studied extracts together with other phenolic acid derivatives. In LC-MS/MS analyses, relative standard deviations (RSD \%) ranged between 0.11-9.47. The correlation values were found to be greater than 0.97 for each investigated analyte.
\end{abstract}

Keywords: Origanum; phenolic compounds; LC-MS/MS; method validation; uncertainty assessment; rosmarinic acid. () 2020 ACG Publications. All rights reserved.

\section{Introduction}

The genus Origanum L. is one of the most important genera in the family of Lamiaceae, the species of which are used as herbal tea and spices. It has attracted significant attention of local people in Turkey due to the aromatic properties of species. Turkey is a vital gene center of diversity of the genus. There are 21 species with three subspecies (24 taxa) and 13 hybrids, of which 25 are endemic [1-3].

\footnotetext{
*Corresponding authors: E-Mail: ahmetcgoren@yahoo.com (A.C. Goren);zuleyhaozer@balikesir.edu.tr (Z.Özer) 
In Turkey, species of the genus Origanum, Thymus L., Satureja L., Thymbra L., Cridothymus L. are called as "Kekik". The Origanum species are known worldwide as "Oregano" and Turkey is the largest supplier of it in the world. In 2019, approximately 15000 tons of Origanum species were harvested and exported as raw material and essential oil [4,5]. A significant part of this quantity is obtained by cultivation of Origanum onites L., and relatively lower part of this amount is collected from nature.

In Turkey, seven Origanum species are commonly used as herbal tea and spice among 37 taxa. Wild or cultivated forms of Origanum vulgare L. is used as a condiment and herbal tea. The species widely distributed from Macaronesia to China and is divided into six subspecies worldwide and four subspecies are distributed in the Flora of Turkey as follows: subsp. gracile (K.Koch) Ietsw., subsp. hirtum (Link) A. Terracc., subsp. viridulum (Martren the-Donosti) Nyman and subsp. vulgare. All those species are used as herbal tea and condiments and, the most common one is O. vulgare subsp. hirtum in Turkey [6].

Apart from herbal tea and condiments, Origanum species have been used in the pharmaceutical, cosmetic, and food industries due to their biological activities [7]. The phytochemical studies on the essential oil of Origanum species have pointed out to the rich presence of thymol and carvacrol [8-10]. Differences in the composition of the essential oils of the $O$. vulgare subsp. hirtum and $O$. vulgare subsp. vulgare species have been the subject of various researchers' reports. Carvacrol, linalool, thymol, $\beta$ caryophyllene, and trans-sabinene hydrate were found to be major components of essential oils of both species [11-26]. Moreover, antimicrobial and antioxidant activities of essential oil and various extracts of $O$. vulgare subsp. hirtum and $O$. vulgare subsp. vulgare were reported [9,18, 22, 27-30]. There is a unique study about the anticholinesterase activity of essential oil of both species [17]. However, there are few studies about the phenolic contents of both species in the literature. The phenolic composition of ethanol, methanol, water, and ethyl acetate extracts of $O$. vulgare subsp. hirtum were investigated in a few studies [31-35]. The main phenolic contents of $O$. vulgare subsp. hirtum were determined as quercetin, kaemferol [31], rosmarinic acid [32-34], apigenin 7-O-beta-D-glucoside [32], caffeic acid [34], apigenin, and luteolin [35]. Total phenolic content of methanol and water extracts of $O$. vulgare subsp. vulgare were reported as well [21, 24]. And, two known phenolics (luteolin 7-O-beta-D-xyloside and luteolin 7-O-beta-D-glucuronide) were isolated from $O$. vulgare subsp. vulgare $n$-butanol extract [36]. To our knowledge, no report is available for the phenolic profile of $O$. vulgare subsp. vulgare in the literature.

Phenolic compounds, the amount of which may differ according to the plants, are the most abundant secondary metabolites in plants. Plants produce phenolic compounds for protection under intense stress. Phenolic compounds are also called "bioflavonoids" because of their positive effects in terms of nutritional physiology. Also, phenolic compounds contribute to various health benefits of plant extracts [37-41].

The aim of this study is to investigate the phenolic profile of $O$. vulgare subsp. hirtum and $O$. vulgare subsp. vulgare by LC-MS/MS. The full method validation and uncertainty evaluation of the developed method are also discussed herein.

\section{Experimental}

\subsection{Plant Material}

O. vulgare subsp. hirtum collected from Muğla, (Köyceğiz, between Beyobası and Çayhisar villages, roadside) in July 2016, and $O$. vulgare subsp. vulgare collected from Artvin (Borçka to Hopa, 17 th km roadside, slopes) in August 2013. The species were identified by Prof. Dr. Tuncay Dirmenci at Bal,kesir University. Voucher specimens were deposited at the Herbarium of Faculty of Education, Balikesir University, Balikesir, Turkey as TD 4591 and TD 3937, respectively. 


\subsection{Preparation of Extracts}

$100 \mathrm{~g}$ of aerial parts of air-dried species were extracted with methanol $(1 \mathrm{~L})$ for 15 days. After filtration and evaporation, it was coded as Methanol-1 (12.23 g). Furthermore, another $100 \mathrm{~g}$ aerial parts of the species were extracted successively by chloroform $(1 \mathrm{~L})$ then with acetone $(1 \mathrm{~L})$ and methanol $(1$ L) for 15 days. After filtration, the solvents were evaporated using a rotary evaporator to give chloroform $(2.43 \mathrm{~g})$, acetone $(4.16 \mathrm{~g})$, and methanol extracts $(10.35 \mathrm{~g})$ and they were coded as Chloroform, Acetone, and Methanol-2, respectively. All the extracts were kept at $-20{ }^{\circ} \mathrm{C}$ until they were used for experimental studies.

\subsection{Preparation of Test Solution for LC-MS/MS}

Each extract weighed (fifty to seventy $\mathrm{mg}$ ) in a round bottom flask and $3 \mathrm{~mL}$ of the ethanol-water mixture $(50: 50 \mathrm{v} / \mathrm{v})$ was added. In order to obtain a good solubility, the flask was gently heated at $60{ }^{\circ} \mathrm{C}$ on an ultrasonic bath $(15 \mathrm{~min}$.) until a clear solution was obtained. Then, the solutions were then transferred into a $5 \mathrm{~mL}$ of volumetric flask, rinsed with a $200 \mu \mathrm{L}$ ethanol-water mixture $(50: 50 \mathrm{v} / \mathrm{v})$ for three times and diluted to volume with a mobile phase. A portion of this stock solution $(1 \mathrm{~mL})$ was transferred into $5 \mathrm{~mL}$ of another volumetric flask, and $30 \mu \mathrm{L}$ of curcumin $(500 \mathrm{mg} / \mathrm{L}$ in methanol) solution was added as internal standard and diluted to the volume with the mobile phase. The solution was filtered through a $0.45 \mu \mathrm{m}$ Millipore Millex-HV filter and the final solution $(1 \mathrm{~mL})$ was transferred into a capped autosampler vial and $10 \mathrm{~mL}$ of sample was injected to $\mathrm{LC}$ for each run. The samples in the auto sampler were kept at $15^{\circ} \mathrm{C}$ during the experiment $[7,10]$.

\subsection{LC-MS Conditions}

Experiments were conducted by a Zivak® HPLC (High performance liquid chromatography) and Zivak® Tandem Gold Triple quadrupole (Istanbul, Turkey) mass spectrometry equipped with a $\mathrm{C}_{18}$ (150 x $3 \mathrm{~mm} ; 3 \mu \mathrm{m}$ ) column (Fortis Technologies, UK) at TUBITAK UME. $2.40 \mathrm{mTorr}$ CID gas pressure, $5000 \mathrm{~V}$ ESI needle voltage, $600 \mathrm{~V}$ ESI (electrospray ionization) shield voltage, $300{ }^{\circ} \mathrm{C}$ drying gas temperature, $50{ }^{\circ} \mathrm{C}$ API housing temperature, $55 \mathrm{psi}$ Nebulizer gas pressure and 40 psi drying gas pressure were determined as optimum ESI parameters [40,42-44]. LC-MS/MS parameters of secondary metabolites and internal standard are given in Table S1 in supporting information.

\subsection{Chemicals}

Kaempferol ( $>90 \%$, Sigma-Aldrich), kaempferol-3-O-glucoside ( $>97 \%$, Sigma-Aldrich), penduletin ( $>97 \%$, Phytolab), quercetin ( $\geq 95 \%$, Sigma-Aldrich), luteolin (95\%, Sigma-Aldrich), luteolin7-O-rutinoside ( $>97 \%$, Carbosynth limited), apigenin (>97\%, TRC Canada), rutin $(\geq 99 \%$, SigmaAldrich), caffeic acid (98\%, Sigma-Aldrich), trans-ferulic acid ( $\geq 99 \%$, Sigma-Aldrich), rosmarinic acid ( $>96 \%$, Sigma-Aldrich), fumaric acid ( $\geq 99 \%$, Sigma-Aldrich), isosakuranetin (>97\%, Phytolab), pcoumaric acid ( $>98 \%$, Sigma-Aldrich), $p$-hydroxy benzoic acid ( $>97 \%$, Sigma-Aldrich), gallic acid (97.5-102.5\%, Sigma-Aldrich), pyrogallol (>98\%, Sigma-Aldrich), salicylic acid (>99\%, SigmaAldrich), vanillin ( $>97 \%$, Sigma-Aldrich), syringic acid ( $>95 \%$, Sigma-Aldrich), salvigenin $(95 \%$, in house isolated), luteolin-5-O-glucoside ( $96 \%$, in house isolated), curcumin (97\%, isolated from Curcuma longa). HPLC grade methanol and ethanol were purchased from Merck (Darmstadt, Germany). Stock solutions of standards were prepared as $200 \mathrm{mg} / \mathrm{L}$ in ethanol-water (50:50, v/v). Calibration solutions were prepared in ethanol-water $(50: 50, \mathrm{v} / \mathrm{v})$ in a linear range $(0.1,0.2,0.5,1,5$ and $10 \mathrm{mg} / \mathrm{L})$. Dilutions were performed using automatic pipette and glass volumetric flasks (A class), which were stored at $20^{\circ} \mathrm{C}$ in glass containers. Curcumin solution was freshly prepared, from which $300 \mu \mathrm{L}$ was used as an Internal Standard (IS) in all LC-MS/MS experiments.

The LODs were determined to be three times larger than while LOQs were determined to be ten times larger than standard deviation [45-48]. The validation procedure and the results of the validation are discussed in the following section. 


\section{Results and Discussion}

\subsection{Optimization of $L C-M S / M S$}

Triple quadrupole mass spectrometry was used due to its fragmented ion stability $[7,10]$ the parent and daughter ions patterns and collision energy optimization studied carefully by the parameters used LC-MS/MS condition. The optimized parameters are given in Table 1. One of the most critical issues of the applied method is the dissolution of plant extracts in the appropriate solvent to get clear and repeatable separation of chromatographic peaks and ionization stability. Regarding previous reports of literature $[7,10]$ and our findings clearly showed that the best mobile phase solution was determined to be a gradient of acidified methanol and water in ESI source for those compounds.

\subsection{Method Validation}

Validation of the applied method was performed using analytical standards of corresponding compounds (see section 2.4) with using the target ions (Table S1) and curcumin was used as an internal standard.

\subsubsection{Linearity}

Calibration curves were obtained from standard calibration solutions. The linearity of the method was assayed by analyzing the calculation of a six-point linear plot in the range of $0.1 \mathrm{mg} / \mathrm{L}$ to $10 \mathrm{mg} / \mathrm{L}$ with six replicates. The linear regression equation and the squared correlation coefficient were determined and are given in Table 1.

Table 1. Method validation parameters of LC-MS/MS for the used phenolic standards

\begin{tabular}{lllccccc}
\hline No & \multicolumn{1}{c}{ Compounds } & $\begin{array}{c}\text { Linear regression } \\
\text { equation }\end{array}$ & $\boldsymbol{R}^{2}$ & $\begin{array}{c}\text { LOD } \\
(\mathbf{m g} / \mathbf{L})\end{array}$ & $\begin{array}{c}\text { LOQ } \\
(\mathbf{m g} / \mathbf{L})\end{array}$ & $\begin{array}{c}\text { Recovery } \\
\mathbf{\%}\end{array}$ & $\begin{array}{c}\text { RSD } \\
\mathbf{\%}\end{array}$ \\
\hline 1 & Kaempferol & $\mathrm{y}=0.0230 \mathrm{x}+0.0116$ & 0.984 & 0.002 & 0.008 & 101.0 & 5.47 \\
2 & Kaempferol-3- $O$-rutinoside & $\mathrm{y}=0.1080 \mathrm{x}+0.0135$ & 0.997 & 0.014 & 0.045 & 95.0 & 8.15 \\
3 & Salvigenin & $\mathrm{y}=0.0355 \mathrm{x}+0.8620$ & 0.991 & 0.036 & 0.119 & 97.4 & 5.21 \\
4 & Penduletin & $\mathrm{y}=0.1630 \mathrm{x}+0.0262$ & 0.996 & 0.089 & 0.297 & 100.8 & 9.47 \\
5 & Quercetin & $\mathrm{y}=0.1150 \mathrm{x}+0.0078$ & 0.993 & 0.001 & 0.002 & 99.0 & 0.11 \\
6 & Luteolin & $\mathrm{y}=0.2120 \mathrm{x}+0.0699$ & 0.993 & 0.062 & 0.207 & 98.9 & 0.16 \\
7 & Luteolin-7-O-glucoside & $\mathrm{y}=0.1350 \mathrm{x}+0.0246$ & 0.995 & 0.022 & 0.072 & 106.3 & 8.56 \\
8 & Luteolin-5- $O$-glucoside & $\mathrm{y}=0.2300 \mathrm{x}+0.0413$ & 0.992 & 0.01 & 0.034 & 98.2 & 1.12 \\
9 & Apigenin & $\mathrm{y}=0.1780 \mathrm{x}+0.0850$ & 0.996 & 0.15 & 0.501 & 99.6 & 4.01 \\
10 & Rutin & $\mathrm{y}=0.0232 \mathrm{x}+0.0008$ & 0.996 & 0.01 & 0.034 & 98.4 & 7.9 \\
11 & Isoquercetin & $\mathrm{y}=0.0115 \mathrm{x}+0.0215$ & 0.995 & 0.199 & 0.665 & 106.4 & 9.42 \\
12 & $p$-Coumaric acid & $\mathrm{y}=0.2670 \mathrm{x}+0.1810$ & 0.977 & 0.006 & 0.021 & 101.2 & 6.39 \\
13 & Caffeic acid & $\mathrm{y}=0.3300 \mathrm{x}+0.0036$ & 0.992 & 0.028 & 0.093 & 102.3 & 8.04 \\
14 & trans-Ferulic acid & $\mathrm{y}=0.0655 \mathrm{x}+0.0266$ & 0.992 & 0.047 & 0.158 & 100.3 & 5.21 \\
15 & Chlorogenic acid & $\mathrm{y}=0.2620 \mathrm{x}+0.0674$ & 0.998 & 0.445 & 1.483 & 99.9 & 5.45 \\
16 & Rosmarinic acid & $\mathrm{y}=0.1960 \mathrm{x}+0.0043$ & 0.998 & 0.022 & 0.072 & 97.3 & 3.73 \\
17 & Fumaric acid & $\mathrm{y}=0.0569 \mathrm{x}+0.0177$ & 0.991 & 0.003 & 0.01 & 97.3 & 5.44 \\
18 & $p$-Hydroxy benzoic acid & $\mathrm{y}=0.1230 \mathrm{x}+0.0280$ & 0.993 & 0.002 & 0.007 & 99.7 & 4.78 \\
19 & Gallic acid & $\mathrm{y}=0.0569 \mathrm{x}+0.0177$ & 0.991 & 0.002 & 0.008 & 100.4 & 4.85 \\
20 & Pyrogallol & $\mathrm{y}=0.0438 \mathrm{x}+0.0073$ & 0.980 & 0.001 & 0.002 & 101.5 & 5.47 \\
21 & Salicylic acid & $\mathrm{y}=0.0255 \mathrm{x}+0.1780$ & 0.970 & 0.211 & 0.704 & 101.3 & 0.21 \\
22 & Vanillin & $\mathrm{y}=0.0982 \mathrm{x}+0.0158$ & 0.998 & 0.019 & 0.064 & 99.6 & 6.57 \\
23 & Syringic acid & $\mathrm{y}=0.0305 \mathrm{x}+0.0079$ & 0.997 & 0.022 & 0.073 & 99.9 & 8.39 \\
\hline
\end{tabular}




\subsection{2. $L O D$ and $L O Q$}

The limit of detection (LODs) of the method for each compound was determined according to the following equation: $\mathrm{LOD}$ or $\mathrm{LOQ}=\kappa \mathrm{SDa} / \mathrm{b}$, where 3 for $\mathrm{LOQ}$ and $\kappa=3$ for LOD, SDa represents the standard deviation of the intercept, and $\mathrm{b}$ represents the slope (Table 1).

\subsubsection{Recovery, Repeatability, and Intermediate Precision}

Before the evaluation recovery, repeatability, and intermediate precision of the method used and screening measurements were done on Methanol-1 and Chloroform extracts. Then, according to the detected levels of compounds in the extracts, we spiked the extracts to reach the final concentrations as $0.1 \mathrm{mg} / \mathrm{L}$ and $0.5 \mathrm{mg} / \mathrm{L}$ and $1 \mathrm{mg} / \mathrm{L}$ in $5 \mathrm{~mL}$ volumetric flasks. Unspiked plant extracts were also analyzed to determine the target compounds concentrations in the blank sample. The recovery of each component at each fortification levels was calculated according to the following formula.

$$
\text { Recovery } \%=\frac{\text { Measured conncentration-endogeneous concentration }}{\text { spiked concentration }} \times 100
$$

The recoveries of measured components were ranged from 95.0 to $106.4 \%$ (Table 1). Mean relative standard deviations (RSD) were found to be 0.1-10\% for all and those data was added to the uncertainty budget of all reported compounds.

The repeatability of the developed method was assessed at three concentration levels of the recovery studies. For the intermediate (reproducibility) precision, a set of spiked samples having three concentration levels were analyzed twice a week for a period of 3 weeks and repeatability of method evaluated.

\subsection{Estimation of Uncertainty}

\subsubsection{Identification of Uncertainty Sources}

The bottom-up approach was applied to obtain the measurement of the uncertainty value for the developed method. The sources for uncertainty were determined as were weighing the sample, calibration graph, and repeatability. Detailed evaluation procedure corresponding equations are given in our previous papers [45-47] and to avoid repetition, we summarized the calculation of combined standard measurement uncertainty of target compounds in plant extracts in equation 2 . The expanded measurement uncertainty was obtained by multiplying the combined standard measurement uncertainty value with 2 (coverage factor) at $95 \%$ confidence level. The uncertainty value of measurement results are given Table 1.

$$
\frac{u_{c}(A)}{C_{A}}=\sqrt{\left(\frac{u\left(W_{S S}\right)}{W_{S S}}\right)^{2}+\left(\frac{u\left(C_{0}\right)}{C_{0}}\right)^{2}+u\left(R_{m}\right)^{2}+u(r)^{2}}
$$

where,

$u_{c}(A)$ : Combined standard measurement uncertainty of the analyte

$C_{A}$ : Concentration of the target analyte

$u\left(W_{S S}\right)$ : Combined standard measurement uncertainty of the sample intake

$W_{s s}$ : Weight of the starting sample

$u\left(c_{0}\right)$ : Combined standard measurement uncertainty of the calibration curve

$c_{0}$ : Determined concentration of the sample by using the calibration curve

$u\left(R_{m}\right)$ : Combined standard measurement uncertainty of recovery

$u(r)$ : Standard measurement uncertainty of repeatability 


\subsection{Secondary Metabolites of $O$. vulgare subsp. hirtum and $O$. vulgare subsp. vulgare}

There are a few studies reporting the phenolic content of various extracts of $O$. vulgare subsp. hirtum. The presence of quercetin, kaempferol, and apigenin was reported in $O$. vulgare subsp. hirtum methanol, water and ethanol extracts [31]. Furthermore, $O$. vulgare subsp. hirtum considered as a good source of rosmarinic acid [32,33]. Moreover, the total phenolic content of methanol extract of $O$. vulgare subsp. hirtum were determined [14,49]. However, no study reported about the comprehensive phenolic composition of $O$. vulgare subsp. vulgare

Table 2. Secondary metabolites of $O$. vulgare subsp. vulgare by LC-MS/MS (mg/kg)

\begin{tabular}{|c|c|c|c|c|}
\hline \multirow{2}{*}{ Compounds } & \multicolumn{4}{|c|}{ Extracts* } \\
\hline & Methanol-1 & Chloroform & Acetone & Methanol-2 \\
\hline \multicolumn{5}{|l|}{ Flavonoids } \\
\hline Kaempferol & $408.95 \pm 28.86$ & - & $80.56 \pm 5.69$ & $135.27 \pm 9.55$ \\
\hline Kaempferol-3-O-Rutinoside & $3.08 \pm 0.28$ & - & - & - \\
\hline Salvigenin & $1.28 \pm 0.09$ & - & - & - \\
\hline Penduletin & $116.5 \pm 11.81$ & - & - & - \\
\hline Isoquercetin & $2.13 \pm 0.61$ & - & - & - \\
\hline Luteolin & $163.14 \pm 41.91$ & - & $18.75 \pm 4.82$ & $50.11 \pm 12.87$ \\
\hline Luteolin-7-O-Glucoside & $74.27 \pm 7.56$ & - & $4.07 \pm 0.41$ & $30.61 \pm 3.12$ \\
\hline Luteolin-5-O-Glucoside & $103.75 \pm 6.68$ & - & $6.48 \pm 0.42$ & $41.44 \pm 2.67$ \\
\hline Apigenin & - & - & - & $46.29 \pm 3.73$ \\
\hline Rutin & $9.58 \pm 0.63$ & - & $2.44 \pm 0.16$ & $4.08 \pm 0.27$ \\
\hline \multicolumn{5}{|l|}{ Phenolic acids } \\
\hline$p$-Hydroxy benzoic acid & - & - & - & $528.98 \pm 42.03$ \\
\hline Caffeic acid & $743.15 \pm 147.06$ & - & $113.53 \pm 22.47$ & $292.09 \pm 57.80$ \\
\hline$p$-Coumaric acid & $28.3 \pm 4.36$ & - & - & - \\
\hline (E)-Ferulic acid & $1256.36 \pm 87.79$ & - & $36.53 \pm 2.55$ & $753.37 \pm 52.64$ \\
\hline Chlorogenic acid & $132.35 \pm 18.33$ & - & $7.85 \pm 1.09$ & $44.24 \pm 6.13$ \\
\hline Rosmarinic acid & $7944.48 \pm 609.18$ & - & $852.97 \pm 65.41$ & $3235.73 \pm 248.11$ \\
\hline \multicolumn{5}{|l|}{ Simple phenolics } \\
\hline Pyrogallol & $18.66 \pm 1.24$ & - & - & $13.91 \pm 0.93$ \\
\hline Vanillin & - & $3.46 \pm 0.32$ & $2.61 \pm 0.24$ & - \\
\hline \multicolumn{5}{|l|}{ Dicarboxylic acid } \\
\hline \multirow{2}{*}{$\begin{array}{l}\text { Fumaric acid } \\
\text { Total identified metabolites } \\
\text { (mg/kg dried herba) }\end{array}$} & $1425.35 \pm 98.85$ & - & $6.00 \pm 0,42$ & $362.74 \pm 25.16$ \\
\hline & 12431 & 3.46 & 1051 & 5538 \\
\hline
\end{tabular}

*Methanol-1: direct methanol extract, Chloroform: chloroform extract, Acetone: acetone extract,

Methanol-2: methanol extract; The uncertainty value was not considered for the total identified metabolites

In this study, the phenolic compounds of $O$. vulgare subsp. vulgare and $O$. vulgare subsp. hirtum. were examined under four groups: flavonoids, phenolic acids, simple phenolics, and the dicarboxylic acids. Rosmarinic acid was determined as the major compound of the species. While the mass fractions of rosmarinic acid were found to be 7944.48 $\pm 609.18,852.97 \pm 65.41$ and $3235.73 \pm 248.11 \mathrm{mg} / \mathrm{kg}$ in the Methanol-1, Acetone, and Methanol-2 extracts of O.vulgare subsp. vulgare, respectively (Table 2), it was determined as $78.26 \pm 6.00,175.13 \pm 13.43$ and $373.91 \pm 28.67 \mathrm{mg} / \mathrm{kg}$, in the extracts $O$. vulgare subsp. hirtum, respectively (Table 3). Chloroform extract of $O$. vulgare subsp. hirtum was identified as rich in flavonoids and penduletin was determined as the major compound $(125.28 \pm 10.22 \mathrm{mg} / \mathrm{kg})$. In addition, Methanol-1 extract of $O$. vulgare subsp. hirtum was identified as rich in caffeic acid $(247.28 \pm 46.13 \mathrm{mg} / \mathrm{kg}$ ) (Table 3). Methanol-2 extracts of both species were identified as the richest extracts for phenolics whereas chloroform extracts of both species were identified as the poorest one. Other contents of secondary metabolites and their concentrations are given in Table 2 and Table 3 . The 
LC-MS/MS chromatograms of phenolic compounds are given in Figure S1 and Figure S2 in the supplementary material.

The difference of the measured amount of substances in Methanol 1, Methanol 2 and sum of the successive solvent extracts, might be due to the acidity of chloroform and atmospheric conditions in acetone and methanol. We know that, "when plant extracts are stored in organic solvents for a long period of time at room temperature and/or under sunlight, there is a risk of artifact formation and decomposition/isomerization of the components. In conclusion, heat, light, air, and $\mathrm{pH}$ are the other factors that may lead to the degradation of natural compounds and differentiate their amount in plant extracts [49]". Thus, we recommend the use of the extractions directly, rather than successive solvent extraction for screening. This study is the most comprehensive data reported for the screening of twentythree different secondary metabolites and nineteen secondary metabolites were identified in the extracts of $O$. vulgare subsp. hirtum and thirteen for $O$. vulgare subsp. vulgare.

This study is the most comprehensive data reported for the screening of twenty-three different secondary metabolites. Nineteen secondary metabolites were investigated for $O$. vulgare subsp. hirtum and thirteen for $O$. vulgare subsp. vulgare.

Table 3. Secondary metabolites of $O$. vulgare subsp. hirtum by LC-MS/MS (mg/kg)

\begin{tabular}{|c|c|c|c|c|}
\hline \multirow{2}{*}{ Compounds } & \multicolumn{4}{|c|}{ Extracts* } \\
\hline & Methanol-1 & Chloroform & Acetone & Methanol-2 \\
\hline \multicolumn{5}{|l|}{ Flavonoids } \\
\hline Kaempferol & $25.02 \pm 1.51$ & - & - & $17.69 \pm 1.30$ \\
\hline Penduletin & $38.32 \pm 4.23$ & $125.28 \pm 10.22$ & - & $59.21 \pm 5.22$ \\
\hline Quercetin & $84.18 \pm 5.32$ & $83.21 \pm 5.31$ & $178.58 \pm 5.14$ & $110.08 \pm 7.02$ \\
\hline Luteolin & - & - & $6.97 \pm 0.35$ & - \\
\hline Apigenin & $30.56 \pm 0.88$ & - & $10.39 \pm 0.92$ & - \\
\hline \multicolumn{5}{|l|}{ Phenolic acids } \\
\hline Gallic acid & - & - & - & $6.65 \pm 0.36$ \\
\hline Salicylic acid & - & - & $84.25 \pm 3.22$ & - \\
\hline Syringic acid & $65.11 \pm 3.55$ & - & - & $154.33 \pm 12.25$ \\
\hline Caffeic acid & $247.28 \pm 46.13$ & $56.58 \pm 11.20$ & - & $140.28 \pm 27.45$ \\
\hline$p$-Coumaric acid & - & - & $35.67 \pm 3.88$ & - \\
\hline Rosmarinic acid & $78.26 \pm 6.00$ & - & $175.13 \pm 13.43$ & $373.91 \pm 28.67$ \\
\hline \multicolumn{5}{|l|}{ Simple phenolics } \\
\hline Pyrogallol & - & - & $25.36 \pm 2.08$ & - \\
\hline \multicolumn{5}{|l|}{ Dicarboxylic acid } \\
\hline Fumaric acid & $39.64 \pm 2.97$ & $35.35 \pm 2.45$ & $79.31 \pm 5.50$ & $12.24 \pm 0.74$ \\
\hline $\begin{array}{c}\text { Total identified metabolites } \\
\text { (mg/kg dried herba) }\end{array}$ & 608 & 300 & 495 & 874 \\
\hline
\end{tabular}

In conclusion, the phenolic composition of the chloroform, acetone, and methanol extracts of $O$. vulgare subsp. hirtum and $O$. vulgare subsp. vulgare were successfully analyzed by validated LC-MS/MS method. The method performances are reported for the first time herein. Rosmarinic acid, caffeic acid, and penduletin were determined as the major phenolic compounds of both species. Methanol extracts of both species are the richest extracts in terms of phenolic compounds. This study supported that $O$. vulgare subsp. hirtum and $O$. vulgare subsp. vulgare species could become a source of potentially bioactive compounds in pharmaceutical and food industries, and the validated method can be used for the screening of secondary metabolites of plant species for the standardization of extracts and dietary supplements. 


\title{
Acknowledgements
}

This work was supported by The Scientific and Technological Research Council of Turkey (TUBITAK) [grant number 113Z225].

\section{Supporting Information}

Supporting Information accompanies this paper on http://www.acgpubs.org/journal/journal-ofchemical-metrology

\author{
ORCID \\ Züleyha Özer: 0000-0003-4957-5756 \\ Sema Çarıçı: 0000-0003-3657-9926 \\ Hasibe Y1lmaz: 0000-0002-1308-1650 \\ Turgut Kıliç: 0000-0002-6842-3160 \\ Tuncay Dirmenci: 0000-0003-3038-6904 \\ Ahmet C. Gören: 0000-0002-5470-130X
}

\section{References}

[1] T. Dirmenci, T. Özcan, T. Yazıc1, T. Arabaci and E. Martin (2018). Morphological, cytological, palynological and molecular evidence on two new hybrids from Turkey: an example of homoploid hybridization in Origanum (Lamiaceae), Phytotaxa. 371, 145-167.

[2] T. Dirmenci, T. Yazıc1, T. Özcan, S. Çelenk and E. Martin (2018). A new species and a new natural hybrid of Origanum L.(Lamiaceae) from the west of Turkey, Turk. J. Bot. 42, 73-90.

[3] T. Dirmenci, T. Özcan, M. Açar, T. Arabac1, T. Yazıcı and E. Martin (2019). A rearranged homoploid hybrid species of Origanum (Lamiaceae): O.x munzurense Kit Tan \& Sorger, Botany. Lett. 166, 153-162.

[4] TÜIK (2019). https://www.tuik.gov.tr Accessed 06.02.2020.

[5] Ç. Bozdemir (2019). Türkiye'de yetişen kekik türleri, ekonomik önemi ve kullanım alanları, Y.Y.U. J. Agr. Sci. 29, 583-594.

[6] T. Dirmenci, T. Kılıç, S. Çelenk, E. Martin, T. Arabacı, B. Yıldız and T. Yazıcı (2017). Taxonomic, karyological, chemical and molecular investigations in Origanum L. (Lamiaceae) species growing in Turkey. TÜBİTAK-KBAG Project (113 Z 225) (in Turkish).

[7] S. Çarıkçı, T. Kılıç, Z. Özer, T. Dirmenci, T. Arabacı and A.C. Gören (2018). Quantitative determination of some phenolics in Origanum laevigatum Boiss extracts via validated LC-MS/MS method and antioxidant activity, J. Chem. Metrol. 12, 121-127.

[8] A.J. Karamanos and D.E. Sotiropoulou (2013). Field studies of nitrogen application on Greek oregano (Origanum vulgare ssp. hirtum (Link) Ietswaart) essential oil during two cultivation seasons, Ind. Crop. Prod. 46, 246-252.

[9] N. Leyva-López, E.P. Gutiérrez-Grijalva, G. Vazquez-Olivo and J.B. Heredia (2017). Essential oils of oregano: Biological activity beyond their antimicrobial properties, Molecules 22, 989.

[10] Z. Özer, A.C. Gören, T. Kılıç, M. Öncü, S. Çarıkçı and T. Dirmenci (2020). The phenolic contents, antioxidant and anticholinesterase activity of section Amaracus (Gled.) Vogel and Anatolicon Ietsw. of Origanum L. species, Arab. J. Chem. 13, 5027-5039.

[11] H.D. Dorman and S.G. Deans (2004). Chemical composition, antimicrobial and in vitro antioxidant properties of Monarda citriodora var. citriodora, Myristica fragrans, Origanum vulgare ssp. hirtum, Pelargonium sp. and Thymus zygis oils, J. Essent. Oil Res. 16, 145-150.

[12] M.M. Özcan, L.G. Pedro, F. Al-Juhaimi, Z. Endes, A.S. Erol, E. Duman and F. Er (2012). Constituents of the Essential oil of Origanum vulgare subsp. hirtum Growing Wild in Turkey, J. Essent. Oil Bear. Pl. 15, 572-576.

[13] S. Kizil, N. Hasimi and V. Tolan (2014). Biological activities of Origanum, Satureja, Thymbra and Thymus species grown in Turkey, J. Essen. Oil Bear. Pl. 17, 460-468.

[14] G. Yaldiz, K. Arici and G. Yilmaz (2017). Phytochemical analysis, antioxidant and antibacterial activities of four Lamiaceae species cultivated in barnyard manure, J. Agric. Sci. 23, 95-108. 
[15] Z. Özer, T. Kiliç, S. Selvi and C. Pasa (2018). Effect of different drying methods and development stages on the essential oil chemical composition of aerial parts of Origanum vulgare L. subsp. hirtum (link) Letsw, J. Essent. Oil Bear. Pl. 21, 1403-1409.

[16] V. Maggini, G. Pesavento, I. Maida, A.L. Nostro, C. Calonico, C. Sassoli, E. Perrin, M. Fondi, A. Mengoni, C. Chiellini, A. Vannacci, E. Perrin, M. Fondi, A. Mengoni and C. Chiellini (2017). Exploring the effect of the composition of three different Oregano essential oils on the growth of multidrug-resistant cystic fibrosis Pseudomonas aeruginosa strains, Nat. Prod. Commun. 12, 1949-1952.

[17] C. Sarikurkcu, G. Zengin, M. Oskay, S. Uysal, R. Ceylan and A. Aktumsek (2015). Composition, antioxidant, antimicrobial and enzyme inhibition activities of two Origanum vulgare subspecies (subsp. vulgare and subsp. hirtum) essential oils, Ind. Crop. Prod. 70, 178-184.

[18] G. Esen, A.D. Azaz, M. Kurkcuoglu, K.H.C. Baser and A. Tinmaz (2007). Essential oil and antimicrobial activity of wild and cultivated Origanum vulgare L. subsp. hirtum (Link) letswaart from the Marmara region Turkey, Flavour. Frag. J. 22, 371-376.

[19] E. Mancini, I. Camele, H.S. Elshafie, L. De Martino, C. Pellegrino, D. Grulova and V. De Feo (2014). Chemical composition and biological activity of the essential oil of Origanum vulgare ssp. hirtum from different areas in the Southern Apennines (Italy), Chem. Biodivers. 11, 639-651.

[20] M. Vazirian, M. Mohammadi, M.H. Farzaei, G. Amin and Y. Amanzadeh (2015). Chemical composition and antioxidant activity of Origanum vulgare subsp. vulgare essential oil from Iran, Res. J. Pharmacog. 2, 41-46.

[21] F. Şahin, M. Güllüce, D. Daferera, A. Sökmen, M. Sökmen, M. Polissiou and H. Özer (2004). Biological activities of the essential oils and methanol extract of Origanum vulgare ssp. vulgare in the Eastern Anatolia region of Turkey, Food. Control. 15, 549-557.

[22] E. De Falco, E. Mancini, G. Roscigno, E. Mignola, O. Taglialatela-Scafati and F. Senatore (2013). Chemical composition and biological activity of essential oils of Origanum vulgare L. subsp. vulgare L. under different growth conditions, Molecules 18, 14948-14960.

[23] J. Radusienne, D. Peciulyte and V. Janulis (2006). Variability and antimicrobial activity of Origanum vulgare subsp. vulgare essential oils. In I International Symposium on the Labiatae: Advances in Production, Biotechnology and Utilisation. 723, 393-398.

[24] J.S. Dambolena, M.P. Zunino, E.I. Lucini, R. Olmedo, E. Banchio, P.J. Bima and J.A. Zygadlo (2010). Total phenolic content, radical scavenging properties, and essential oil composition of Origanum species from different populations, J. Agr. Food Chem. 58, 1115-1120.

[25] R. Nurzyńska-Wierdak, A. Bogucka-Kocka, I. Sowa and G. Szymczak (2012). The composition of essential oil from three ecotypes of Origanum vulgare L. ssp. vulgare cultivated in Poland, Farmacia 60, 571-577.

[26] V. Davidenco, C. Vega and J.A. Argüello (2012). Photoperiodic response in Origanum vulgare ssp. vulgare and ssp. hirtum Ietsw. impact on development and growth, Rev. Fac. Cienc. Agrar. 44, 1-12.

[27] S. Karakaya, S.N. El, N. Karagözlü and S. Şahin (2011). Antioxidant and antimicrobial activities of essential oils obtained from oregano (Origanum vulgare ssp. hirtum) by using different extraction methods, J. Med. Food. 14, 645-652.

[28] S. Kizil, N. Hasimi and V. Tolan (2014). Biological activities of Origanum, Satureja, Thymbra and Thymus species grown in Turkey, J. Essen. Oil Bear. Pl. 17, 460-468.

[29] O.E. Özkan, K. Güney, M. Gür, E.S. Pattabanoğlu, E. Babat and M.M. Khalifa (2017). Essential oil of oregano and savory: Chemical composition and antimicrobial activity, Ind. J. Pharm. Educ. Res. 51, 205208.

[30] B. Kulaksiz, S. Er, N. Üstündağ-Okur and G. Saltan-İşcan (2018). Investigation of antimicrobial activities of some herbs containing essential oils and their mouthwash formulations, Turk. J. Pharm. Sci. 15, 370375.

[31] K. Karaboduk, O. Karabacak, H. Karaboduk and T. Tekinay (2014). Chemical analysis and antimicrobial activities of the Origanum vulgare subsp. hirtum, J. Environ. Prot. Ecol. 15, 1283-1292.

[32] G. Özkan and M.M. Özcan (2014). Some phenolic compounds of extracts obtained from Origanum species growing in Turkey, Environm. Monit. Assess. 186, 4947-4957.

[33] S. Gülsoy (2012). Evaluation of essential oils and phenolic compounds of some Origanum (Labiatae/Lamiaceae) taxonomy, Asian. J. Chem. 24, 2479-2483.

[34] C. Koukoulitsa, C. Zika, G.D. Geromichalos, V.J. Demopoulos and H. Skaltsa (2006). Evaluation of aldose reductase inhibition and docking studies of some secondary metabolites, isolated from Origanum vulgare L. ssp. hirtum, Bioorg. Med. Chem. 14, 1653-1659.

[35] A. Tair, E.K. Weiss, L.M. Palade, S. Loupassaki, D.P. Makris, E. Ioannou, V. Roussis and P. Kefalas (2014). Origanum species native to the island of Crete: in vitro antioxidant characteristics and liquid chromatography-mass spectrometry identification of major polyphenolic components, Nat. Prod. Res. 28, 1284-1287. 
[36] M. Gulluce, M. Karadayi, Z. Guvenalp, H. Ozbek, T. Arasoglu and O. Baris (2012). Isolation of some active compounds from Origanum vulgare L. ssp. vulgare and determination of their genotoxic potentials, Food Chem. 130, 248-253.

[37] M. Karapandzova, G. Stefkov, I.C. Karanfilova, T.K. Panovska, J.P. Stanoeva, M. Stefova and S. Kulevanova (2019). Chemical characterization and antioxidant activity of Mountain Pine (Pinus mugo Turra, Pinaceae) from Republic of Macedonia, Rec. Nat. Prod. 13, 50-63.

[38] G. Wang, J. Zheng, J. Yang, Y. Sun, N. Zhang, H. Liu and J. Liu (2019). Phenolic derivatives from Dioscorea bulbifera, Rec. Nat. Prod. 13, 301-306.

[39] P. Sun, T. Kang, H. Xing, Z. Zhang, D. Yang, J. Zhang, P.V. Paré and M. Li (2019). Phytochemical changes in aerial parts of Hypericum perforatum at different harvest stages, Rec. Nat. Prod. 13, 1-9.

[40] S.D. Hatipoglu (2016). Phenolic acid contents of Salvia poculata Nab by LC-MS/MS, J. Chem. Metrol. 10, 12-15.

[41] M. Li, P.W. Pare, J. Zhang, T. Kang, Z. Zhang, Y. Delong, K. Wang and H. Xing (2018). Antioxidant capacity connection with phenolic and flavonoid content in Chinese medicinal herbs, Rec. Nat. Prod. 12, 239-250.

[42] H. Yılmaz, S. Çarıkçı, T. Kılıç, T. Dirmenci, T. Arabacı and A.C. Gören (2017). Screening of chemical composition, antioxidant and anticholinesterase activity of section Brevifilamentum of Origanum (L.) species, Rec. Nat. Prod. 11, 439-455.

[43] S. Baki, A.N. Tufan, M. Altun, F. Özgökçe, K. Güçlü and M. Özyürek (2018). Microwave-assisted extraction of polyphenolics from some selected medicinal herbs grown in Turkey, Rec. Nat. Prod. 12, 2939

[44] H. Han, H. Yılmaz and İ. Gülçin (2018). Antioxidant activity of flaxseed (Linum usitatissimum L) shell and analysis of its polyphenol contents by LC-MS/MS, Rec. Nat. Prod. 12, 397-402.

[45] S.B. Oguzkan, B. Karagul, E.S. Aksoy, A. Uzun, M. Can, H. Yilmaz, H.I. Ugras, B. Binici and A. C. Goren (2018). Determination of taxanes by validated LC-MS/MS method in hazelnut collected from different regions and altitudes in Turkey, J. Chem. Metrol. 12, 26-33.

[46] A.C. Gören, G. Şahin, İ. Gümilcineli and B. Binici (2018). Rapid and reliable 25-OH vitamin D2 and $25-$ $\mathrm{OH}$ vitamin D3 measurements by multitasker LC-MS/MS, J. Chem. Metrol. 12, 17-25.

[47] A.C. Gören, G. Bilse and M. Bilsel (2007). Rapid and simultaneous determination of 25-OH-vitamin D2 and D3 in human serum by LC/MS/MS: Validation and uncertainty assessment, J.Chem.Metrol. 1, 1-9.

[48] W. Srinuanchai, R. Nooin, S. Jarussophon, K. Kasemwong and O. Nuchuchua (2019). Determination of gymnemic acid level in Gymnema inodorum leaves using multiple reaction monitoring mass spectrometry, J.Chem. Metrol. 13, 75-79.

[49] A. Kurca and E. Arslan (2008). Antioxidant capacity and total phenolic content of selected plants from Turkey, Int. J. Food Sci. Tech. 43, 2038-2046.

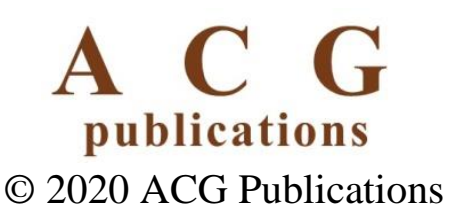

